\title{
Influence of Copper Additives on the Viscosity and Stratification of Iron Melt
}

\author{
O. A. Chikova ${ }^{a}$, V. S. Tsepelev ${ }^{a}$, A. N. Konstantinov ${ }^{b}$, and V. V. V'yukhin ${ }^{a}$ \\ ${ }^{a}$ Ural Federal University \\ ${ }^{b}$ Ural State Pedagogical University \\ Received March 14, 2013
}

\begin{abstract}
Viscosimetric data are obtained for $\mathrm{Fe}-\mathrm{Cu}$ melts in heating and subsequent cooling of samples with $0-10 \mathrm{wt} \% \mathrm{Cu}$. Above the liquidus in the resulting phase diagram, the boundaries of the region where microheterogeneities of colloidal scale exist in the melt are found.
\end{abstract}

DOI: $10.3103 / \mathrm{S} 0967091213050045$

In steel and cast iron, copper is an effective alloying element. It ensures considerable strengthening of the alloys; increases the corrosion resistance; improves the deformability of steels; modifies the antifrictional properties and wear resistance of cast iron and graphitized steel; improves the hardenability of iron and steel; and significantly affects the crystallization and recrystallization processes in complex alloys [1]. In the United States, steel with the addition of $\mathrm{Cu}$ in place of $\mathrm{Nb}$ and $\mathrm{V}$ has been proposed. The copper-rich nanoparticles formed in $\alpha$-Fe on cooling result in dispersional hardening of the steel and ensure high plasticity and fracture resistance [2]. Although the strengthening effect of copper precipitates has been known for a long time, we do not understand this process or know precisely which factors affect the formation of copper nanodeposits. The clear effect of bcc $\mathrm{Cu}$ deposits on the mechanical properties of $\alpha$-Fe has prompted interest in the structural state and thermodynamic and elastic properties of solid and liquid $\mathrm{Fe}-\mathrm{Cu}$ solutions - in particular, in the factors that affect the solidification and stratification of $\mathrm{Fe}-\mathrm{Cu}$ alloys and the behavior of the liquidus in this system. Contradictory data have been obtained regarding the compatibility of $\mathrm{Cu}$ and $\mathrm{Fe}$ in the liquid state [3]. The phase diagram of the $\mathrm{Fe}-\mathrm{Cu}$ system includes a region of immiscibility in the supercooled melt (supercooling to $100^{\circ} \mathrm{C}$ or more); the stratification of $\mathrm{Fe}-\mathrm{Cu}$ alloys into two phases, rich in iron and copper, respectively, occurs below the liquidus [4]. By a combination of differential thermal analysis, electron microscopy, and $\mathrm{X}$-ray microspectral analysis, we may establish not only the metastable stratification of the melt (critical point $1704 \mathrm{~K} ; x_{\mathrm{Fe}}=0.53$ ) but also metastable solidification to $\mathrm{L} \longrightarrow \delta$ phase in the range $x_{\mathrm{Fe}}=0.43-0.96$ and metastable synthetic transformation $\mathrm{L}_{1}+\mathrm{L}_{2} \Leftrightarrow \varepsilon$ at $1405 \mathrm{~K}$ [3].

We argue that homogenizing heat treatment of the liquid metal is a promising means of suppressing the stratification of $\mathrm{Fe}-\mathrm{Cu}$ melt and producing $\alpha-\mathrm{Fe}$ that is supersaturated with copper [5]. This method permits the production of massive ingots of monotectic alloys with the required structure in natural gravitation, even at relatively low cooling rates, and also of supersaturated solid solutions for systems with a phase diagram of eutectic type [5].

The fundamental assumption here is that small droplets of colloidal scale that are enriched with one of the components may exist beyond the immiscibility region in the liquid metal for a long time. Their destruction entails heating to a temperature $T_{\text {hom }}$, which will be different for each composition, or some other energy input to the melt. After such heating, the melt is irreversibly converted to a true solution, with significant change in the solidification conditions.

Experiments show that the destruction of the microheterogeneous structure of monotectic and eutectic melts is usually accompanied by anomalous temperature dependences of the liquid metal's properties - in particular, its viscosity. The temperature dependences of the melt viscosity corresponding to heating and subsequent cooling of the sample will then be different. In this case, the temperature $T_{\text {hom }}$ corresponding to irreversible transition to a homogeneous state of the melt is determined from the onset of the high-temperature region where the heating and cooling polytherms coincide. In experiments with monotectic melts, anomalously large spread of the kinematic viscosity is observed; in many cases, the correct value cannot be determined. On heating to specific temperatures for each composition, this spread is irreversibly reduced to values corresponding to the random measurement error. In this case, the temperatures corresponding to destruction of the microstratified state of the melt are determined from the irreversible decrease in the spread of the kinematic viscosity [6,7].

In the present work, we investigate the viscosity of $\mathrm{Fe}-\mathrm{Cu}$ melts as a function of the temperature and the 

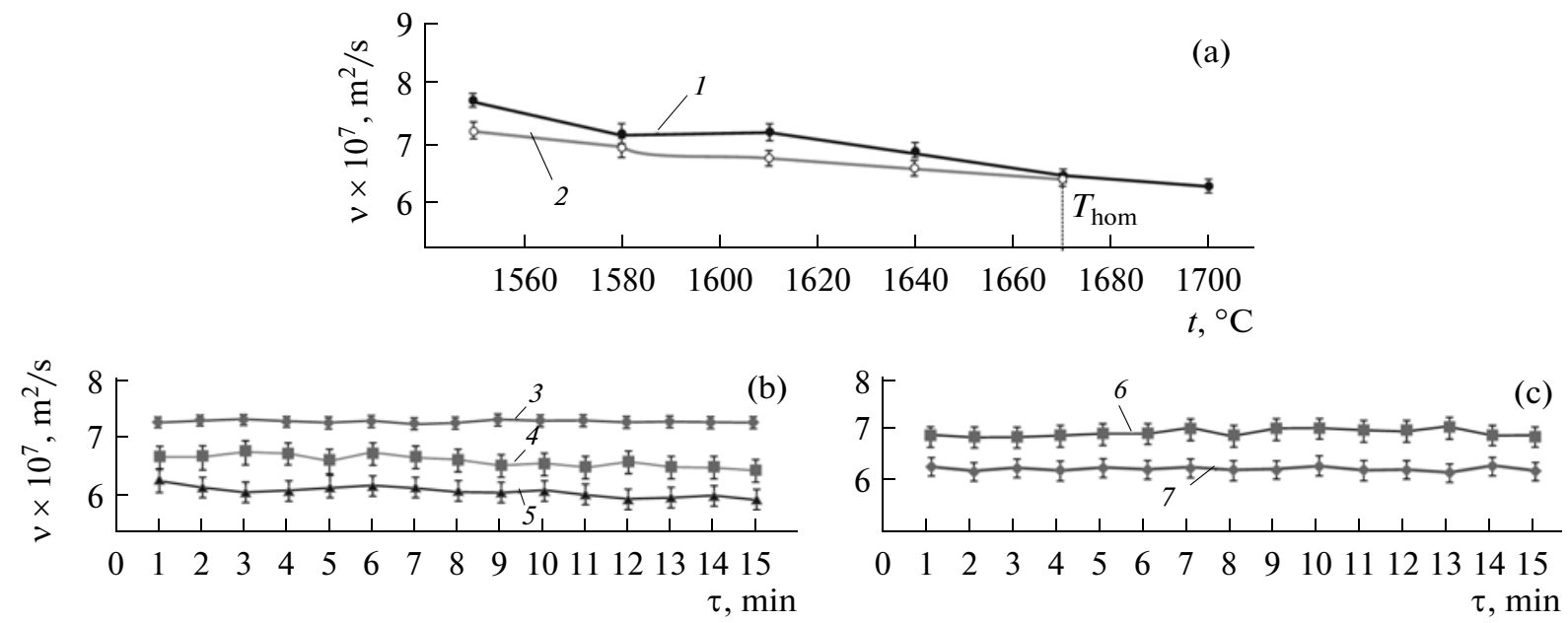

Fig. 1. Temperature (a) and time (b, c) dependences of the kinematic viscosity of $\mathrm{Fe}-0.5 \mathrm{wt} \% \mathrm{Cu}$ melt: (1) heating; (2) cooling; (3-5) heating at 1550,1650 , and $1700^{\circ} \mathrm{C}$, respectively; $(6,7)$ cooling at 1650 and $1550^{\circ} \mathrm{C}$, respectively.
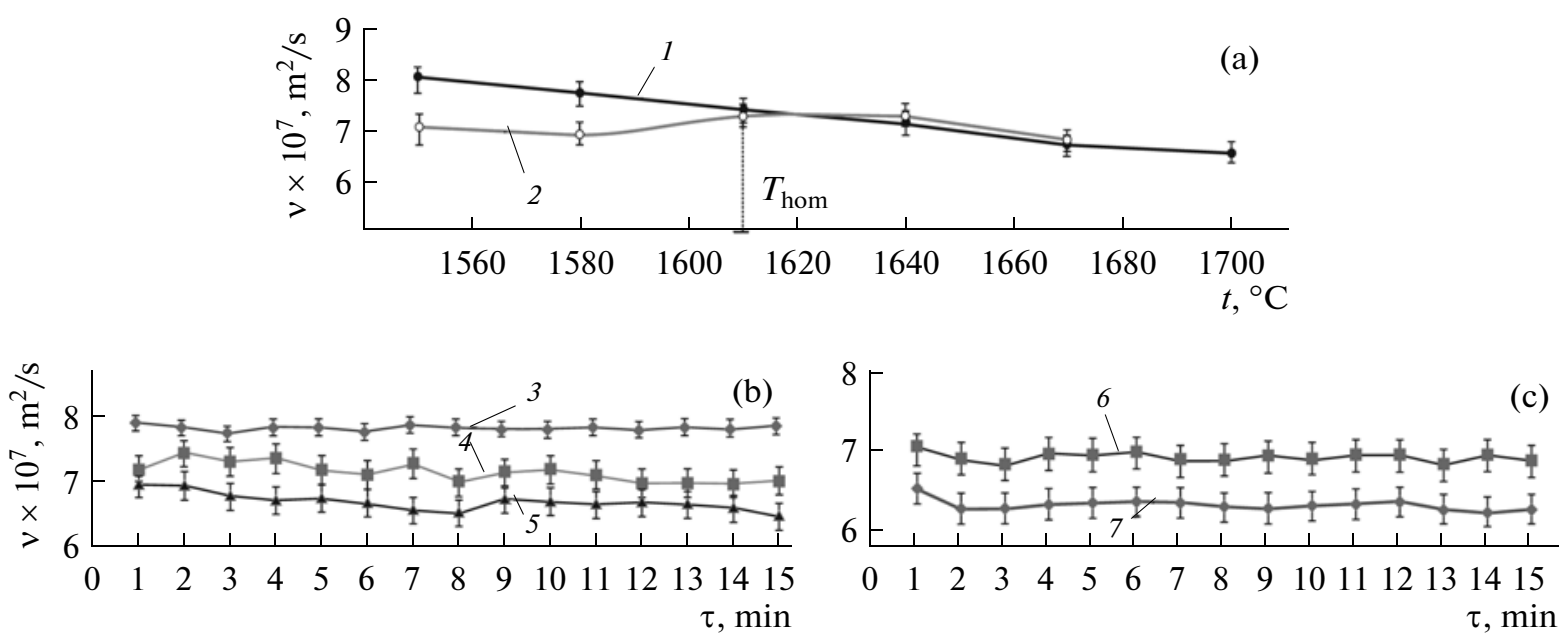

Fig. 2. Temperature (a) and time (b, c) dependences of the kinematic viscosity of $\mathrm{Fe}-1 \mathrm{wt} \% \mathrm{Cu}$ melt: notation as in Fig. 1.

time, so as to determine the homogenization temperatures with $0-10 \mathrm{wt} \% \mathrm{Cu}$.

We consider alloys with $0,0.5,1.0,3.0,5.0$, and $10.0 \mathrm{wt} \% \mathrm{Cu}$. The viscosity $v$ is measured by means of damping torsional oscillations of a crucible with the melt in heating and subsequent cooling within the range $1550-1700^{\circ} \mathrm{C}$. The temperature dependence is measured in isothermal holding (at least $30 \mathrm{~min}$ ) with relatively small temperature increments $\left(10-15^{\circ} \mathrm{C}\right)$. The systematic error of the $v(T)$ measurements is $3 \%$, while the random error, determining the spread of the points within a single experiment, is no more than $1.5 \%$ at a confidence level $p=0.95$. The time dependence of the viscosity is measured in individual experiments. At each temperature, 15 successive measurements are made. The temperature is maintained at the specified value to within $1^{\circ} \mathrm{C}$ by means of a high-precision regulator. In the measurements, the oscillation parameters are recorded optically, by a photographic system. Detailed description of the experimental apparatus, the measurement of the time and temperature dependences of the kinematic viscosity, and the analysis of the experimental data may be found in [8-10]. The materials employed are M00k copper and carbonyl iron ingots. In all the experiments, $\mathrm{BeO}$ crucibles are used. The experiments are conducted in high-purity helium at $10^{5} \mathrm{~Pa}$.

In Figs. 1-5, we show viscosimetric data for $\mathrm{Fe}-\mathrm{Cu}$ melts. The temperature dependence of the viscosity for pure iron is consistent with [11]. For all the $\mathrm{Fe}-\mathrm{Cu}$ melts, the heating and cooling polytherms are different; in other words, hysteresis is present (Figs. 1-5). In some experiments, as we see in the table, there is increased spread of the kinematic viscosity on heating, which is consistent with experiments using monotectic $\mathrm{Al}-\mathrm{In}, \mathrm{Al}-\mathrm{Pb}$, and $\mathrm{Ga}-\mathrm{Pb}$ melts $[6,7,12]$. 

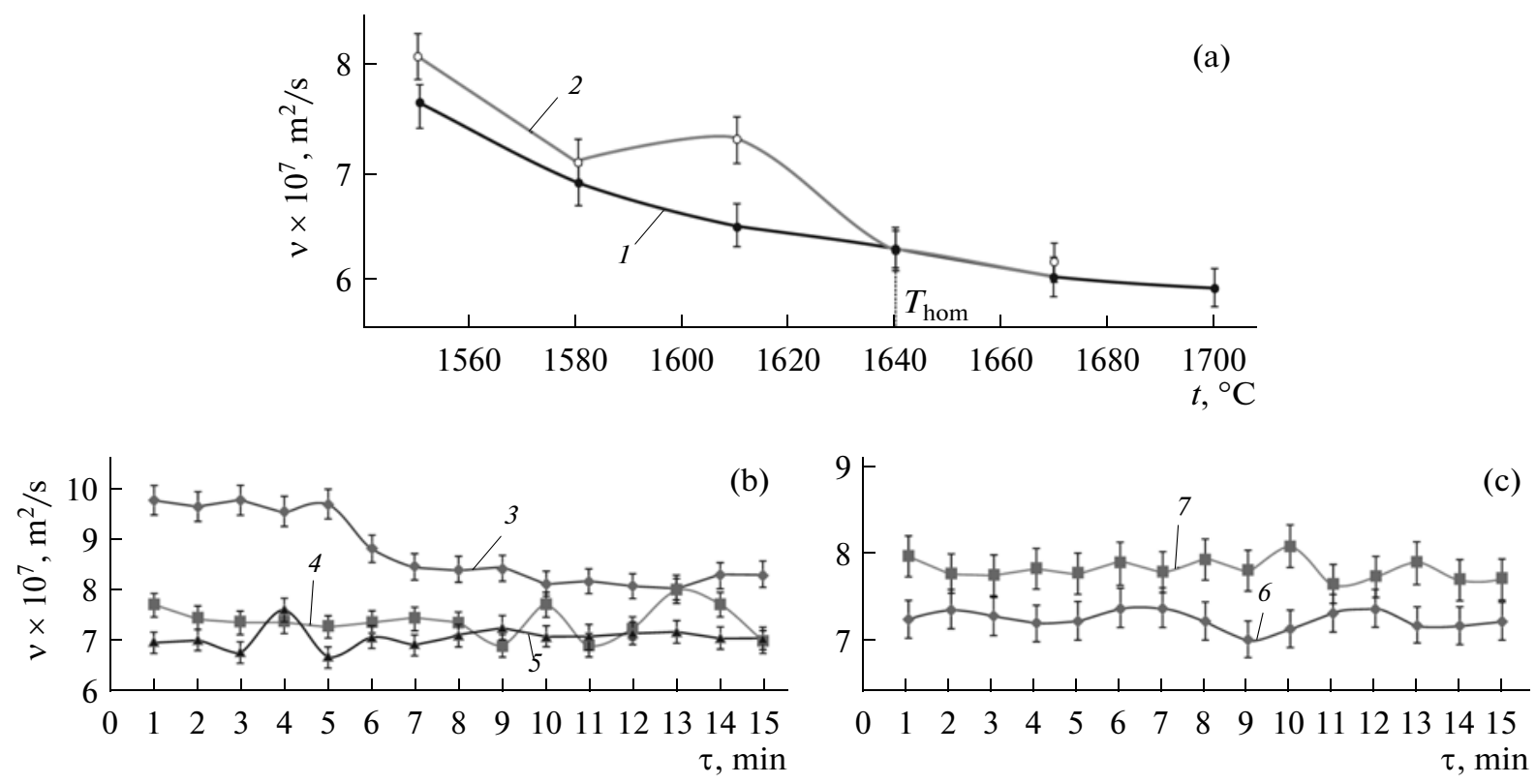

Fig. 3. Temperature (a) and time (b, c) dependences of the kinematic viscosity of $\mathrm{Fe}-3 \mathrm{wt} \% \mathrm{Cu}$ melt: notation as in Fig. 1.
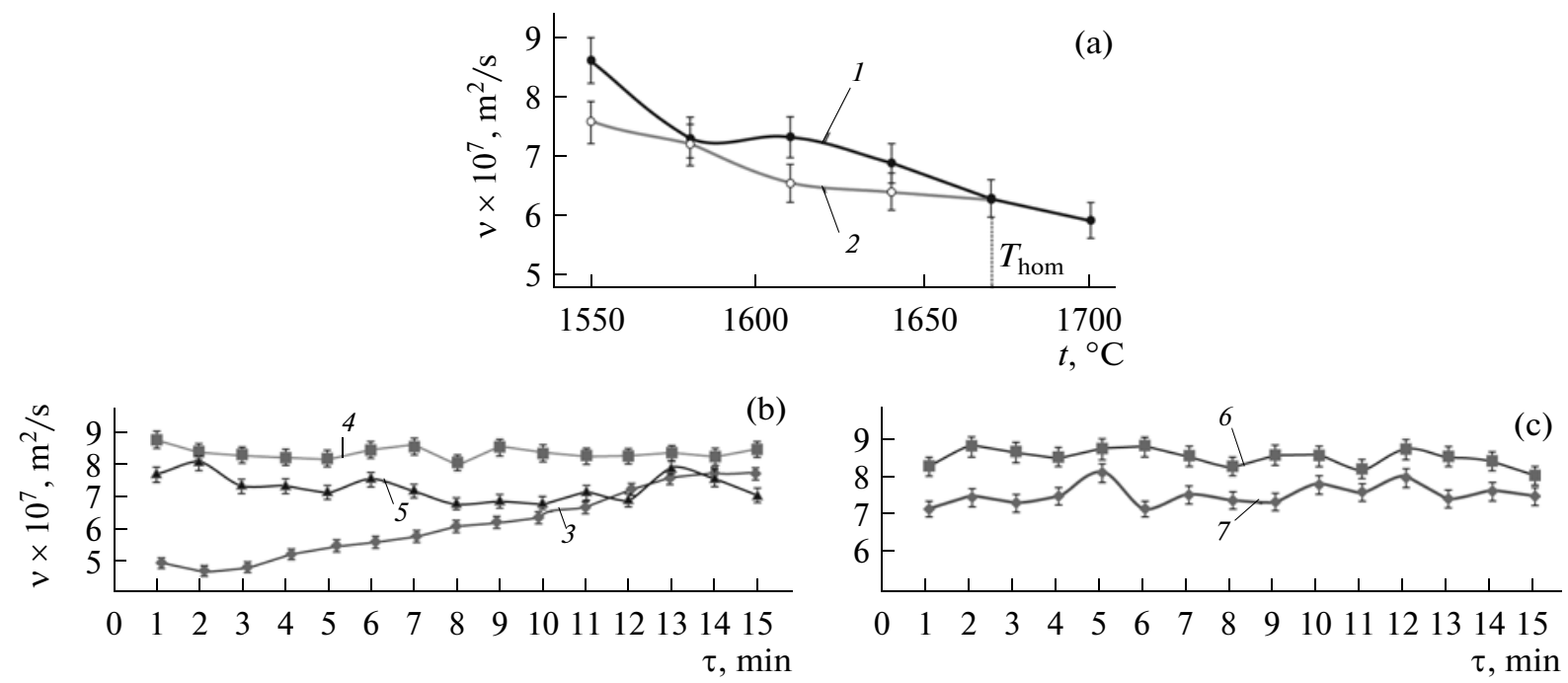

Fig. 4. Temperature (a) and time (b, c) dependences of the kinematic viscosity of $\mathrm{Fe}-5 \mathrm{wt} \% \mathrm{Cu}$ melt: notation as in Fig. 1.

For $\mathrm{Fe}-3 \% \mathrm{Cu}$ and $\mathrm{Fe}-10 \% \mathrm{Cu}$ melts, the viscosity is higher on cooling than on heating. On the polytherms for $\mathrm{Fe}-10 \% \mathrm{Cu}$ melt, the kinematic viscosity on heating and cooling is not the same in the hightemperature region. This may be associated with dispersion of the inherited microheterogeneities in the melt [13].

In correlation analysis of the time dependences, we calculate the mean square deviation of the kinematic viscosity $\sigma \times 10^{7}, \mathrm{~m}^{2} / \mathrm{s}$, and the Pearson correlation coefficient $S$ (shown in the table) [14]. The Pearson method is used on the basis that the strength of the relation between the melt's viscosity and the time must be precisely established, in quantitative terms. We find that the mean square deviation of the kinematic viscosity is no greater than that for iron melt in analogous conditions. The mean square deviation of the kinematic viscosity for iron melt is no more than $0.07 \times 10^{-7} \mathrm{~m}^{2} / \mathrm{s}$, which corresponds to the stated random error of the measurements $(3 \%)$. The Pearson correlation coefficient for the time dependences of the viscosity of iron melt is no more than 0.3 , which corresponds to a weak correlation. For the time dependences of the $\mathrm{Fe}-\mathrm{Cu}$ melt viscosity on heating, the Pearson correlation coefficient is 0.7 , which corresponds to a strong correlation, as we see in the table. This is associated with 

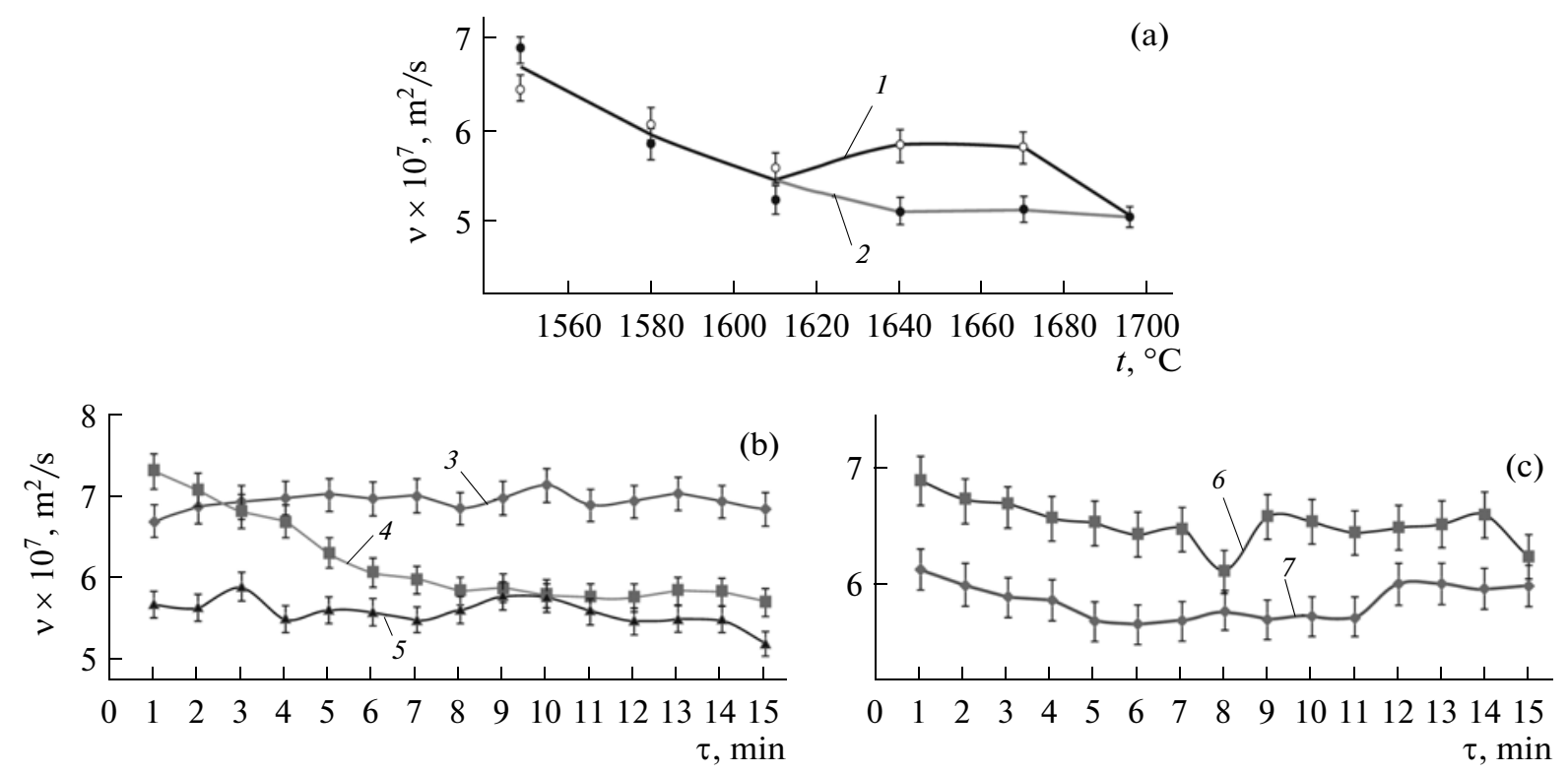

Fig. 5. Temperature (a) and time (b, c) dependences of the kinematic viscosity of $\mathrm{Fe}-10 \mathrm{wt} \% \mathrm{Cu}$ melt: notation as in Fig. 1.

relaxation in the melt due to the destruction of inherited microheterogeneities [13].

The results may be interpreted in terms of the metastable microheterogeneity of liquid alloys [5]. In this approach, we assume that a solution of copper in iron that is uniform at the atomic level is not formed immediately on passing through the macrostratification peak [15]. Rather, the microstratified state persists over some temperature range. In that range, where the microheterogeneity is relatively pronounced, the viscosity values are unstable. Judging from the branching of the $v(T)$ curves, we may say that the conversion of the melt to a true solution occurs close to this branch point. The temperature $T_{\text {hom }}$ at which the melt passes irreversibly to a homogeneous state may be determined from the onset of the hightemperature region where the heating and cooling polytherms coincide. With increase in $\mathrm{Cu}$ content in the melt, $T_{\text {hom }}$ rises; for the $\mathrm{Fe}-10 \% \mathrm{Cu}$ melt, it is above $1700^{\circ} \mathrm{C}$ (Fig. 5). Above $T_{\text {hom }}$, the $\mathrm{Fe}-\mathrm{Cu}$ melt is converted irreversibly to a true solution, according to the data in [5]. That significantly changes the solidification conditions of the metal, even at industrial cooling rates, and may be expected to suppress the stratification of liquid metal and to yield $\alpha-F e$ that is supersaturated with copper.

\section{CONCLUSIONS}

Viscosimetric data have been obtained for $\mathrm{Fe}-\mathrm{Cu}$ melts with $0.5,1.0,3.0,5.0$, and $10.0 \mathrm{wt} \% \mathrm{Cu}$ in heating and subsequent cooling.

For all the alloys, the polytherms of the kinematic viscosity are different in heating and cooling.
In all the experiments, the spread of viscosity values in the region of heterogeneous states is increased on heating and irreversibly reduced on cooling.

We have determined the temperature $T_{\text {hom }}$ corresponding to irreversible transition to a homogeneous

Mean square deviation of the kinematic viscosity $\sigma \times 10^{7} \mathrm{~m}^{2} / \mathrm{s}$ and Pearson correlation coefficient $S$ of the kinematic viscosity and the time for $\mathrm{Fe}-\mathrm{Cu}$ melts

\begin{tabular}{|c|c|c|c|c|}
\hline$T,{ }^{\circ} \mathrm{C}$ & $\sigma_{\text {heat }}$ & $\sigma_{\text {cool }}$ & $S_{\text {heat }}$ & $S_{\text {cool }}$ \\
\hline \multicolumn{5}{|c|}{$\mathrm{Fe}-1$ wt $\% \mathrm{Cu}$} \\
\hline 1550 & 0.010 & 0.013 & 0.09 & 0.30 \\
\hline 1650 & 0.038 & 0.018 & 0.79 & 0.52 \\
\hline 1700 & 0.034 & & 0.76 & \\
\hline \multicolumn{5}{|c|}{$\mathrm{Fe}-3 \mathrm{wt} \% \mathrm{Cu}$} \\
\hline 1550 & 0.176 & 0.030 & 0.89 & 0.26 \\
\hline 1650 & 0.079 & 0.027 & 0.10 & 0.25 \\
\hline 1700 & 0.053 & & 0.20 & \\
\hline \multicolumn{5}{|c|}{$\mathrm{Fe}-0.5 \mathrm{wt} \% \mathrm{Cu}$} \\
\hline 1550 & 0.006 & 0.018 & 0.30 & 0.45 \\
\hline 1650 & 0.027 & 0.011 & 0.85 & 0.20 \\
\hline 1700 & 0.024 & & 0.82 & \\
\hline \multicolumn{5}{|c|}{$\mathrm{Fe}-5$ wt $\% \mathrm{Cu}$} \\
\hline 1550 & 0.321 & 0.059 & 0.92 & 0.4 \\
\hline 1650 & 0.046 & 0.069 & 0.23 & 0.3 \\
\hline 1700 & 0.133 & & 0.34 & \\
\hline \multicolumn{5}{|c|}{$\mathrm{Fe}-10$ wt $\% \mathrm{Cu}$} \\
\hline 1550 & 0.027 & 0.048 & 0.27 & 0.55 \\
\hline 1650 & 0.139 & 0.040 & 0.89 & 0.02 \\
\hline 1700 & 0.042 & & 0.57 & \\
\hline
\end{tabular}


state for $\mathrm{Fe}-\mathrm{Cu}$ melts with $0.5,1.0,3.0,5.0$, and 10.0 wt \% Cu. With increase in Cu content in the melt, $T_{\text {hom }}$ rises; for the $\mathrm{Fe}-10 \% \mathrm{Cu}$ melt, it is above $1700^{\circ} \mathrm{C}$. Heating the $\mathrm{Fe}-\mathrm{Cu}$ melt above $T_{\text {hom }}$ significantly changes the solidification conditions of the metal, even at industrial cooling rates, and may be expected to suppress the stratification of liquid metal and to yield $\alpha-\mathrm{Fe}$ that is supersaturated with copper.

\section{REFERENCES}

1. Sil'man, G.I., Kamynin, V.V., and Goncharov, V.V., Metallov. Term. Obrab. Met., 2007, no. 8, pp. 18-22.

2. Gornostyrev, Yu.N., Kar'kin, I.N., and Kar'kina, L.E., Fiz. Tverd. Tela, 2011, vol. 53, no. 7, pp. 1317-1324.

3. Chigaev, V.V., Kasov, V.D., Turchanin, M.A., and Serov, I.V., Vost.-Evrop. Zh. Pered. Tekhnol., 2005, no. 2, pp. 41-46.

4. Diagrammy sostoyaniya dvoinykh metallicheskikh sistem: Spravochnik (Phase Diagrams of Binary Metallic Systems: A Handbook), Lyakishev, N.P., Ed., Moscow: Mashinostroenie, 1996, vol. 2.

5. Brodova, I.G., Popel', P.S., Barbin, N.M., et al., Iskhodnye rasplavy kak osnova formirovaniya struktury $i$ svoistv alyuminievykh splavov (Initial Melts as the Basis for the Structure and Properties of Aluminum Alloys), Yekaterinburg: UrO RAN, 2005.
6. Popel', P.S., Chikova, O.A., Brodova, I.G., and Polents, I.V., Fiz. Met. Metallov., 1992, no. 9, pp. 111115.

7. Kolobova, T.D., Chikova, O.A., and Popel', P.S., Metally, 2003, no. 6, pp. 32-35.

8. Tyagunov, G.V., Tsepelev, V.S., Kushnir, M.N., and Yakovlev, G.N., Zavod. Lab., 1980, no. 10, pp. 919920.

9. Povodator, A.M., Konashkov, V.V., V'yukhin, V.V., and Tsepelev, V.S., Russian Patent 2386948, Byull. Izobret., 2010, no. 11.

10. Povodator, A.M., Konashkov, V.V., V'yukhin, V.V., and Tsepelev, V.S., Russian Patent 104721, Byull. Izobret., 2011, no. 14A.

11. Vasin, M.G. and Lad'yanov, V.I., Vestn. Udmurtsk. Univ., Fiz., 2005, no. 4, pp. 99-116.

12. Sukhanova, T.D., Chikova, O.A., Popel', P.S., and Brodova, I.G., Rasplavy, 2000, no. 6, pp. 11-15.

13. Chikova, O.A., Rasplavy, 2008, no. 9, pp. 54-64.

14. Povodator, A.M., Konashkov, V.V., V'yukhin, V.V., and Tsepelev, V.S., Steel Trans., 2012, vol. 42, no. 2, pp. 107-109.

15. Chikova, O.A., Vityunin, M.A., Chentsov, V.P., and Sakun, G.V., Kolloid. Zh., 2010, vol. 72, no. 2, pp. 1-7.

Translated by B. Gilbert 